\title{
The Effect of Glutamate Receptor Agonists on Mouse Retinal Astrocyte $\left[\mathrm{Ca}^{2+}\right]_{\mathrm{i}}$
}

\author{
Stephanie N. Blandford ${ }^{1,2}$ and William H. Baldridge ${ }^{1,2,3}$ \\ ${ }^{1}$ Retina and Optic Nerve Research Laboratory, Dalhousie University, Halifax, Nova Scotia, Canada B3H 4R2 \\ ${ }^{2}$ Department of Medical Neuroscience, Dalhousie University, Halifax, Nova Scotia, Canada B3H 4R2 \\ ${ }^{3}$ Department of Ophthalmology \& Visual Sciences, Dalhousie University, Halifax, Nova Scotia, Canada B3H 4 R2
}

Correspondence should be addressed to William H. Baldridge; wbaldrid@dal.ca

Received 3 March 2016; Revised 18 May 2016; Accepted 22 May 2016

Academic Editor: Jun Zhang

Copyright (C) 2016 S. N. Blandford and W. H. Baldridge. This is an open access article distributed under the Creative Commons Attribution License, which permits unrestricted use, distribution, and reproduction in any medium, provided the original work is properly cited.

\begin{abstract}
Calcium-imaging techniques were used to determine if mouse retinal astrocytes in situ respond to agonists of ionotropic ( $\alpha$-amino-3-hydroxy-5-methyl-4-isoxazolepropionic acid, AMPA; N-methyl-D-aspartate, NMDA) and metabotropic (S-3,5dihydroxyphenylglycine, DHPG; trans-1-amino-1,3-cyclopentanedicarboxylic acid, ACPD) glutamate receptors. In most cases we found no evidence that retinal astrocyte intracellular calcium ion concentration $\left(\left[\mathrm{Ca}^{2+}\right]_{\mathrm{i}}\right)$ increased in response to these glutamate agonists. The one exception was AMPA that increased $\left[\mathrm{Ca}^{2+}\right]_{\mathrm{i}}$ in some, but not all, mouse retinal astrocytes in situ. However, AMPA did not increase $\left[\mathrm{Ca}^{2+}\right]_{\mathrm{i}}$ in mouse retinal astrocytes in vitro, suggesting that the effect of AMPA in situ may be indirect.
\end{abstract}

\section{Introduction}

Historically astrocytes were regarded as structural components of the nervous system parenchyma, with few functional attributes. This view changed when astrocytes in vitro and in situ were found to possess receptors for many neurotransmitters including glutamate, adenosine, $\gamma$-aminobutyric acid (GABA), and epinephrine (for review see [1-3]). Activation of astrocyte neurotransmitter receptors commonly results in an increase in cytosolic calcium concentration $\left(\left[\mathrm{Ca}^{2+}\right]_{\mathrm{i}}\right)$ that could lead to calcium-dependent release of chemical transmitters, termed gliotransmitters (for review see [4]).

The effect of glutamate, the predominant excitatory neurotransmitter in the CNS, on astrocytes has been well documented in the brain. Early experiments using acutely isolated hippocampal astrocyte cultures showed that application of glutamate resulted in an initial spike-like rise in $\left[\mathrm{Ca}^{2+}\right]_{\mathrm{i}}$ followed by a sustained $\left[\mathrm{Ca}^{2+}\right]_{\mathrm{i}}$ increase [5]. Further, astrocytes in hippocampal slices showed increased $\left[\mathrm{Ca}^{2+}\right]_{\mathrm{i}}$ following exposure to glutamate released from Shaffer collaterals upon stimulation [6,7]. Astrocyte activation and calcium mobilization caused by glutamate lead to the subsequent release of gliotransmitters, such as adenosine triphosphate (ATP) and D-serine $[8,9]$. Numerous studies have revealed that both metabotropic and ionotropic glutamate receptors are expressed by brain astrocytes and that activation of these receptors commonly results in measureable increases in $\left[\mathrm{Ca}^{2+}\right]_{\mathrm{i}}[1,7,9-12]$.

There are two types of macroglia in the mammalian retina: astrocytes and Müller cells. Anatomically, astrocytes are confined to the nerve fibre layer (NFL), whereas Müller cells run radially from the vitreal surface, or the inner limiting membrane, to the outer limiting membrane. Several studies have suggested that Müller cells are involved in neurovascular coupling mediated by ATP, both as the recipient of the neuron-to-glia signal and as the source of ATP released from glia onto retinal vessels [13-16].

Glutamate is the primary excitatory neurotransmitter in the retina and, therefore, could potentially contribute to neuronal-glia signalling in the retina. Müller cells in some [17, 18] but not all [19] types of vertebrate retinas show increased $\left[\mathrm{Ca}^{2+}\right]_{\mathrm{i}}$ in response to glutamate or glutamate receptor agonists. It is not clear if retinal astrocytes respond to glutamate and if such responses involve an 
increase in $\left[\mathrm{Ca}^{2+}\right]_{\mathrm{i}}$. A study of rabbit retinal astrocytes in situ [20] demonstrated that glutamate and $\alpha$-amino-3-hydroxy-5methyl-4-isoxazolepropionic acid (AMPA) agonists evoked inward currents. Glutamate-evoked currents were blocked by the AMPA/kainate ionotropic glutamate receptor antagonist 6-cyano-7-nitroquinoxaline-2,3-dione (CNQX). N-Methyl$\mathrm{D}$-aspartate (NMDA) did not evoke currents in these astrocytes [20]. In contrast, when applied to rat retinal astrocytes in situ, glutamate did not evoke $\left[\mathrm{Ca}^{2+}\right]_{\mathrm{i}}$ increases [19].

In the present study we used calcium-imaging techniques to determine if mouse retinal astrocytes in situ respond to agonists of ionotropic and metabotropic glutamate receptors. In most cases we find no evidence to suggest that retinal astrocytes are responsive to glutamate agonists. The one exception was AMPA that increased $\left[\mathrm{Ca}^{2+}\right]_{i}$ in some, but not all, mouse retinal astrocytes in situ. However, AMPA did not increase $\left[\mathrm{Ca}^{2+}\right]_{\mathrm{i}}$ in mouse retinal astrocytes in vitro, suggesting that the action of AMPA in situ may be indirect.

\section{Materials and Methods}

The Dalhousie University Committee on Laboratory Animals (UCLA) approved all protocols, and procedures were performed in accord with regulations established by the Canadian Council on Animal Care (CCAC). All chemicals were obtained from Sigma-Aldrich (Oakville, ON, Canada) unless stated otherwise.

2.1. Animals and Husbandry. C57BL/6 mice were purchased from Charles River (St. Constant, Quebec, Canada) and housed at the Carleton Animal Care Facility in the Tupper Medical building at Dalhousie University. Animals were kept in cages with up to four other mice and had access to food and water ad libitum.

2.2. Tissue Preparation. Animals were sacrificed by a lethal intraperitoneal injection of sodium pentobarbital (CDMV, Dartmouth, NS, Canada). Upon confirmation of death, the animal's eyes were removed quickly and placed in room temperature Hanks' Balanced Salt Solution (HBSS) bubbled with $100 \%$ oxygen and proton buffered with $10 \mathrm{mM}$ HEPES ( $\mathrm{pH}$ 7.4). Astrocytes in situ were loaded with calcium dye by electroporation. Calcium indicator dye $(750 \mathrm{~nL}$ of a $20 \mathrm{mM}$ fura-2 pentapotassium salt solution; Invitrogen, Burlington, $\mathrm{ON}$, Canada) was injected into the eye through the optic disk using a Hamilton syringe. Tweezertrodes (BTX, Holliston, MA, USA) were positioned on the eye with the anode on the cornea and square wave current pulses were applied using the ECM 830 electroporation system (BTX). The eyes were electroporated with five square $20 \mathrm{~ms}$ current pulses of $30 \mathrm{~V}$ at $1 \mathrm{~Hz}$. Retinas were isolated by careful dissection and the vitreous humour removed by gentle tweezing with forceps. Retinas were flat mounted on black filter paper (Millipore) with the vitreal surface facing up, secured in place with a platinum ring, and maintained for 10-15 minutes in oxygenated HBSS prior to being transferred to a microscopemounted superfusion chamber for calcium imaging.
2.3. Preparation of Isolated Retinal Astrocyte Cultures. Isolated retinas from 2-3 C57BL/6 mice (Charles River) were added to $5 \mathrm{~mL} \mathrm{Mg}^{2+}$ - and $\mathrm{Ca}^{2+}$-free Dulbecco's Phosphate Buffered Saline (DPBS; Invitrogen) containing $56 \mu \mathrm{L}$ papain (16.5 units/mL, 29.4 units/mg of protein; Worthington) and $50 \mu \mathrm{L} 0.004 \%$ DNase (Worthington). Retinas were incubated in this solution at $37^{\circ} \mathrm{C}$ for $30 \mathrm{~min}$. Following incubation, the papain solution was aspirated from the retinas. Next, $400 \mu \mathrm{L}$ of media composed of $45 \mathrm{~mL}$ Dulbecco's Modified Eagle Medium (DMEM; Invitrogen), $5 \mathrm{~mL}$ Fetal Bovine Serum (FBS; Hemoglobin $\leq 20 \mathrm{mg} / \mathrm{dL}$ ), and $100 \mu \mathrm{L}$ Penicillin Streptomycin (Pen/Strep, 10,000 units/mL; Invitrogen), hereafter simply referred to as media, was added, and retinas were gently triturated. Glass coverslips $(12 \mathrm{~mm})$ were washed overnight in $70 \%$ ethanol on a shaker. The next morning, they were rinsed three times in distilled water and autoclaved for $20 \mathrm{~min}$. Autoclaved coverslips were placed in Nunc 4well plates and coated with Poly-D-Lysine (PDL; $10 \mu \mathrm{g} / \mu \mathrm{L}$ ) for one hr and then rinsed three times in distilled water. Cells were plated on the prepared coverslips and stored in wells containing media in an incubator at $37^{\circ} \mathrm{C}$ for at least 14 days to allow cells to grow. Media were changed every 2-3 days. For calcium imaging individual coverslips were incubated in $5 \mu \mathrm{M}$ fura-2-acetoxymethyl ester (AM; Invitrogen) dissolved in $100 \%$ oxygenated HBSS (10 mM HEPES, pH 7.4, $1 \mu \mathrm{g} / \mathrm{mL}$ pluronic acid) for one hour before being transferred to a superfusion chamber mounted on a microscope.

2.4. Calcium Imaging. Single retinas or coverslips containing cultured retinal astrocytes were placed in a superfusion chamber $(\sim 750 \mu \mathrm{L}$ volume $)$ and superfused with $100 \%$ oxygenated HBSS (10 mM HEPES, pH 7.4) at a rate of $\sim 2 \mathrm{~mL} / \mathrm{min}$. Retinas were imaged with a charge-coupled device (CCD) camera (Sensicam, PCO, Germany) connected to a Zeiss Axioskop microscope equipped with a 40x water immersion objective and recorded using Axon Imaging Workbench 4 software (Molecular Devices, Sunnyvale, CA, USA). Images were typically acquired at a frequency of one frame per $20 \mathrm{sec}$, increased to one frame per $5 \mathrm{sec}$ during periods of drug applications. Ratiometric fura-2 dyes $\left(K_{d}=224 \mathrm{nM}\right)$ were used, and image pairs at 340 and $380 \mathrm{~nm}$ excitation $(510 \mathrm{~nm}$ emission) were collected.

2.5. Experimental Protocol. In whole mount retinas, astrocytes loaded with fura-2 were identified based on stereotypical morphological characteristics [19], including a flattened cell body with a series of radiating processes, forming a layer, positioned within the nerve fibre layer, that can be identified in whole mount preparations as just superficial (vitreal) to neurons (also loaded somewhat with fura-2) in the ganglion cell layer, and (frequently, but not always) forming perivascular endfeet on retinal blood vessels. The effect of ionotropic glutamate receptor agonist on astrocyte calcium levels was tested by exposing astrocytes to ionotropic glutamate receptor agonists (10 $\mu \mathrm{M}$ AMPA or $50 \mu \mathrm{M}$ NMDA), the general metabotropic glutamate receptor agonist trans-1-amino-1,3-cyclopentanedicarboxylic acid monohydrate (ACPD, at $50 \mu \mathrm{M}$ ), or the group I metabotropic agonist (S)-3,5-dihydroxyphenylglycine (DHPG, at $50 \mu \mathrm{M}$ ) 


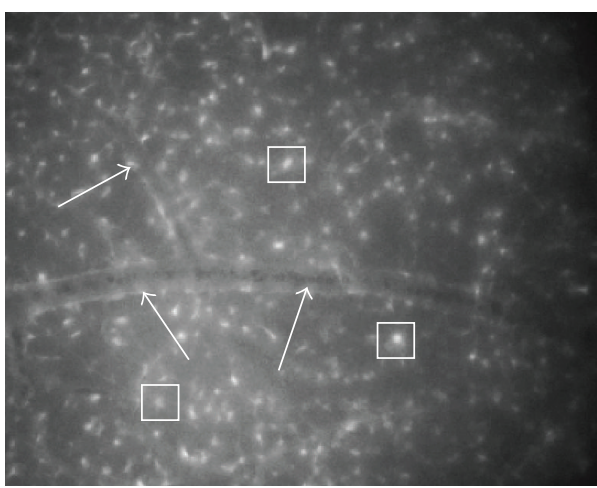

(a)

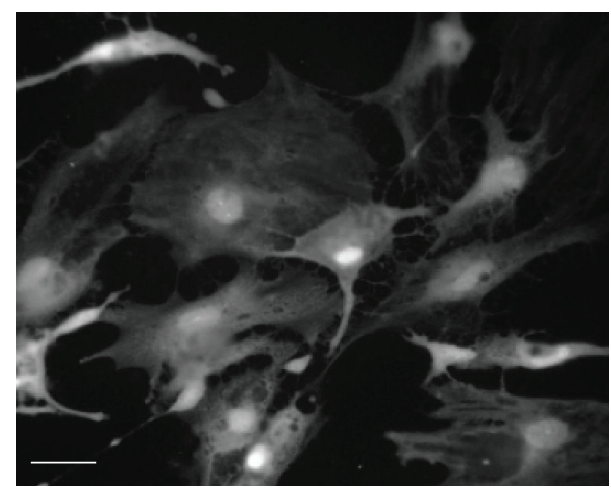

(b)

Figure 1: Photomicrographs illustrating loading of astrocytes with fura- 2 and imaged at $380 \mathrm{~nm}$ excitation and $510 \mathrm{~nm}$ emission. (a) Astrocytes in the retinal whole mount preparation (in situ) loaded with fura-2 by electroporation. Numerous astrocytes are loaded; some examples are highlighted within boxes. A blood vessel can been seen with fura-2-loaded presumptive perivascular endfeet (arrows). (b) Astrocytes in vitro loaded with fura-2. Scale bar (for both (a) and (b)) $50 \mu \mathrm{m}$.

dissolved in the superfusate solution, for $30 \mathrm{sec}$. Each preparation was treated with one agonist two to four times. To assess cell viability, and to contrast responses to the effect of the glutamate agonists, the calcium response induced by $10 \mu \mathrm{M}$ ATP was also tested in most astrocytes studied.

2.6. Data Analysis. Using Axon Imaging Workbench (AIW), identified astrocytes were circled post hoc as a region of interest (ROI). The software provided measures of fluorescence ratio with respect to time for each ROI. Statistical analysis was conducted using Prism 6 (GraphPad, La Jolla, CA, USA).

Baseline ratios were analyzed to assess fluctuations (noise) over $3 \mathrm{~min}$ periods prior to agonist treatments. Agonist-induced calcium dynamics were determined as the peak change $(\Delta f)$ from baseline $(f)$ during a 3 min period following the onset of a $30 \mathrm{~s}$ agonist application. Peak $\Delta f$ for each agonist application was averaged for each cell, and averages for each cell were used to calculate the mean peak $\Delta f$ of each retina or coverslip. For each condition mean baseline, agonist- and ATP-induced $\Delta f$ values were compared using the Kruskal-Wallis test and Dunn's multiple comparisons test.

\section{Results}

3.1. Loading Astrocytes with Calcium Indicator Dye. Electroporation has proven an effective means to load retinal neurons in situ with calcium indicator dye [21-24]. We made the serendipitous discovery that by reversing the polarity of the electroporation electrodes on the eye (placing the anode on the anterior pole and the cathode on the posterior pole) there was strong loading of astrocytes with calcium indicator dye (Figure 1(a)). Astrocytes loaded with dye (in this case fura-2) were identified based on stereotypical morphological characteristics [19] including a flattened cell body with a series of radiating processes, forming a layer, positioned within the NFL, that can be identified in whole mount preparations near to blood vessels with perivascular endfeet contacts on retinal blood vessels. Isolated astrocytes were loaded with fura-2 by conventional means (incubation in solution containing membrane-permeable fura-2 AM; Figure 1(b)).

\subsection{Effect of AMPA and NMDA on $\left[\mathrm{Ca}^{2+}\right]_{i}$ in Retinal} Astrocytes In Situ. Bath application of $10 \mu \mathrm{M}$ AMPA elicited an increase of fura-2 fluorescence ratio in many but not all mouse retinal astrocytes studied in situ. Figure 2(a) shows a trace from a representative astrocyte treated twice with $10 \mu \mathrm{M}$ AMPA and, at the conclusion of the experiment, $10 \mu \mathrm{M}$ ATP. The response to ATP was robust whereas the response to AMPA was smaller, but discernable. Mean data from all astrocytes studied in 5 different retinas (139 astrocytes) are illustrated in Figure 2(b). Although the mean peak response to both AMPA and ATP was increased relative to baseline (a measure of the fluctuations over $3 \mathrm{~min}$ prior to agonist treatment), and the results of the Kruskal-Wallis test indicated that there was a significant difference in mean peak $\Delta f$ (baseline, AMPA- and ATP-treated; $H=11.58 ; p<0.0001$ at $\alpha=0.05)$, Dunn's multiple comparison tests revealed that there was only a significant difference between baseline and the mean peak response to ATP (Figure 2(b)). Another way to assess this data $[10,25]$ is to consider how many astrocytes responded to treatment, defined by reaching a minimum increase of calcium dye fluorescence signal. We defined a responding cell as one that showed an increase in fura-2 fluorescence ratio $\geq 0.02$ from mean baseline during treatment (and this exceeded 2 standard deviations associated with mean baseline fluorescence). $45 \%$ of all astrocytes studied showed an increase $(\Delta f)$ of fura- 2 fluorescence ratio $\geq$ 0.02 in response to $10 \mu \mathrm{M}$ AMPA. All cells (100\%) responded to $10 \mu \mathrm{M}$ ATP. The number of cells that responded $(\Delta f \geq 0.02)$ to ATP but not AMPA (55\% of all cells studied) limits the comparison of the mean data. That a significant number of cells (45\% of all cells studied) responded to AMPA suggests that at least some astrocytes show increases in $\left[\mathrm{Ca}^{2+}\right]_{\mathrm{i}}$ in response to AMPA application in situ. 


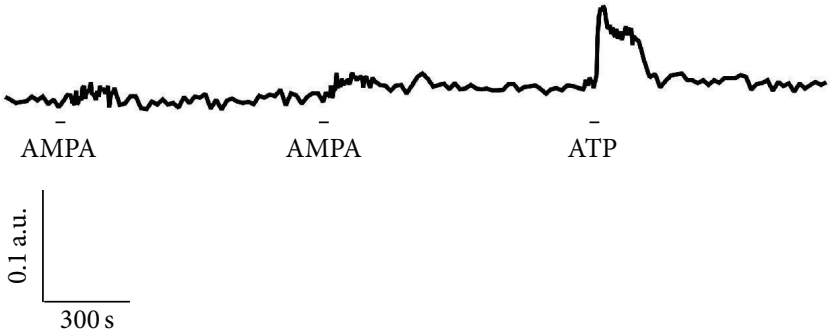

(a)

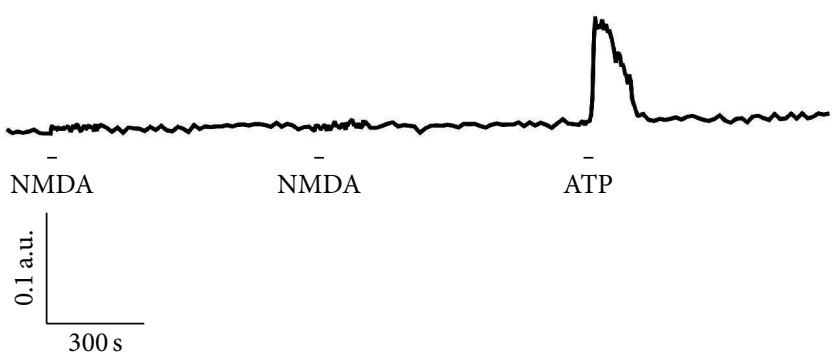

(c)

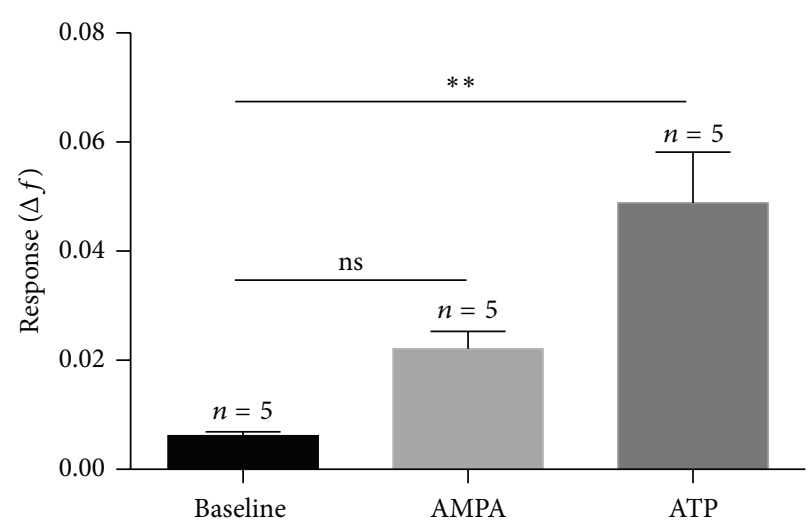

(b)

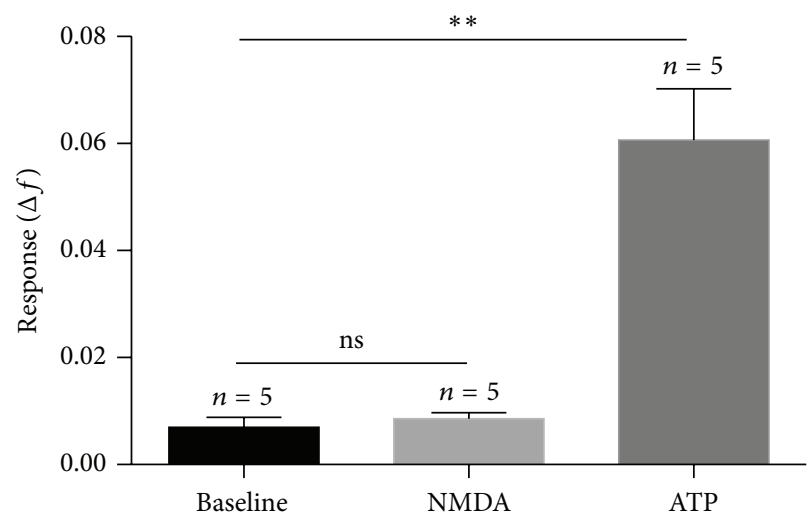

(d)

FIGURE 2: Effect of ionotropic glutamate receptor agonists AMPA and NMDA on retinal astrocytes $\left[\mathrm{Ca}^{2+}\right]_{\mathrm{i}}$ in situ. (a) Representative trace showing fura- 2 fluorescence ratio of an astrocyte treated twice with $10 \mu \mathrm{M}$ AMPA followed by $10 \mu \mathrm{M}$ ATP. The astrocyte showed a small, but discernable, response to both treatments with $10 \mu \mathrm{M}$ AMPA and a larger response to $10 \mu \mathrm{M}$ ATP. (b) The mean response elicited by AMPA was not significantly different from baseline, but the mean response elicited by ATP was. (c) Representative trace showing fura-2 fluorescence ratio of an astrocyte treated twice with $10 \mu \mathrm{M}$ NMDA followed by $10 \mu \mathrm{M}$ ATP. The astrocyte responded to ATP, but not NMDA. (d) Mean response elicited by NMDA application was not significantly different from baseline, while mean response elicited by ATP was. Responses are reported as the average peak change $(\Delta f)$ from baseline $(f)$ during a $3 \mathrm{~min}$ period following $30 \mathrm{~s}$ agonist applications. Error bars are SEM, $n$ $=$ number of retinas studied, ns: not significant; ${ }^{* *} p<0.01$ at $\alpha=0.05$ as determined by Dunn's multiple comparisons test following Kruskal Wallis ANOVA.

Bath applications of $50 \mu \mathrm{M}$ NMDA typically did not elicit a response from mouse retinal astrocytes in situ (Figures 2(c) and $2(\mathrm{~d})$ ). Figure $2(\mathrm{c})$ shows a trace from a representative cell treated twice with $50 \mu \mathrm{M}$ NMDA and then $10 \mu \mathrm{M}$ ATP. The mean peak $\Delta f$ measured from the 5 retinas studied (179 astrocytes) during NMDA treatment was indistinguishable from baseline (Figure 2(d)). The Kruskal-Wallis test revealed that there was a significant difference between mean peak $\Delta f$ (baseline, NMDA-, and ATP-treated; $H=9.620, p=$ 0.0018 ), but this difference was due solely to the effect of ATP (Dunn's multiple comparisons test; Figure 2(d)). Of the 179 astrocytes studied, only 3 cells (2\%) showed an increase in fura- 2 fluorescence ratio of $\geq 0.02$ during treatment with $50 \mu \mathrm{M}$ NMDA. All cells (100\%) responded to $10 \mu \mathrm{M}$ ATP.

3.3. Effect of DHPG and ACPD on $\left[\mathrm{Ca}^{2+}\right]_{i}$ in Retinal Astrocytes In Situ. Bath application of the group I metabotropic glutamate receptor agonist DHPG $(50 \mu \mathrm{M})$ did not elicit a significant response from mouse retinal astrocytes in situ
(Figures 3(a) and 3(b)). Figure 3(a) shows a trace from a representative astrocyte treated twice with $50 \mu \mathrm{M}$ DHPG followed by treatment with a single treatment with $10 \mu \mathrm{M}$ ATP. ATP increased the ratio of fura-2 fluorescence but DHPG had no effect. A similar result was found for mean data from astrocytes studied in 5 different retinas (364 cells) (Figure 3(b)). Statistical analysis (Figure 2(b)) indicated that there was a significant difference between baseline and the mean peak response to ATP (Kruskal-Wallis $H=12.12, p=$ 0.0023 followed by Dunn's multiple comparison tests). Of the 364 astrocytes studied, only 8 cells (2\%) showed an increase in fura-2 fluorescence ratio of $\geq 0.02$ during treatment with $50 \mu \mathrm{M}$ DHPG. All cells (100\%) responded to $10 \mu \mathrm{M}$ ATP.

Similarly, bath applications of the general metabotropic glutamate receptor agonist ACPD $(50 \mu \mathrm{M})$ did not elicit a significant response from mouse retinal astrocytes in situ (Figures 3(c) and 3(d)). The Kruskal-Wallis test revealed that there was a significant difference between mean peak $\Delta f$ (baseline, ACPD-, and ATP-treated; $H=9.62, p=0.0081$ ), 


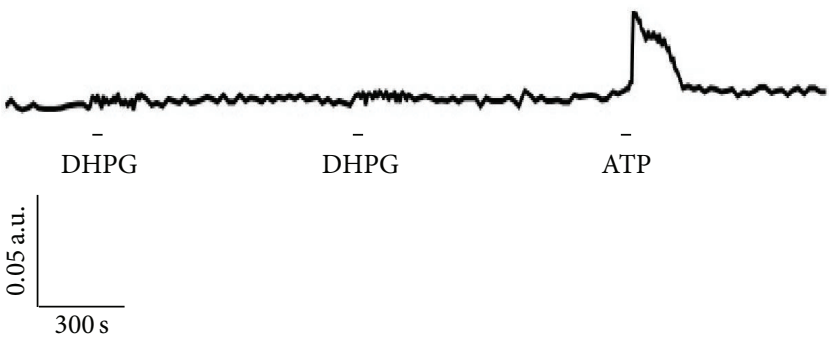

(a)

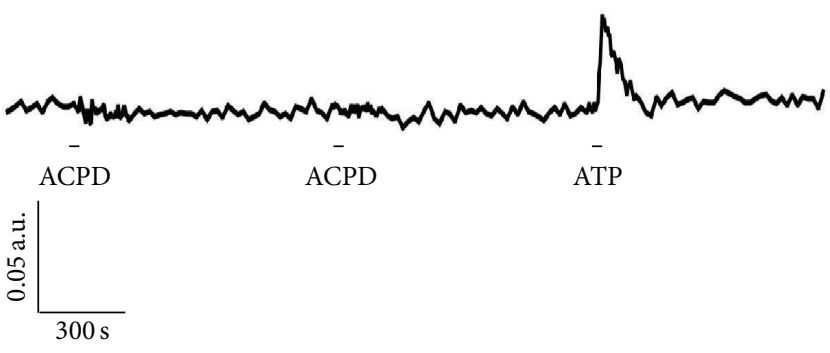

(c)

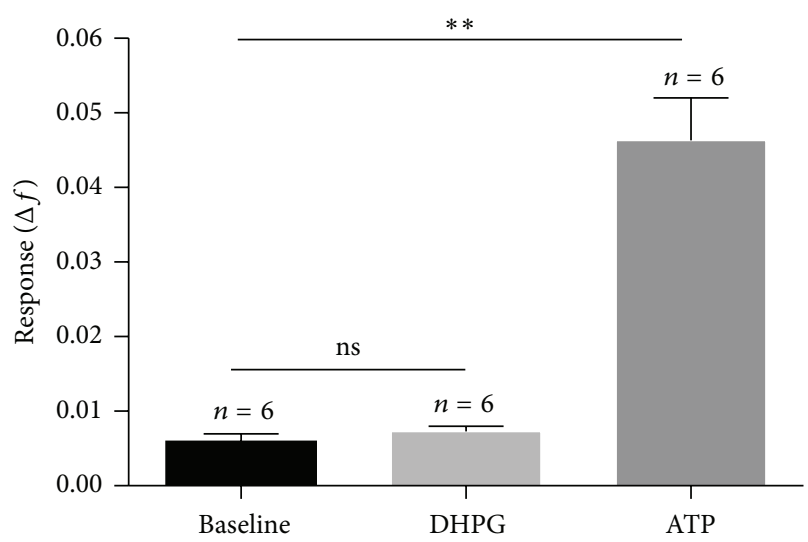

(b)

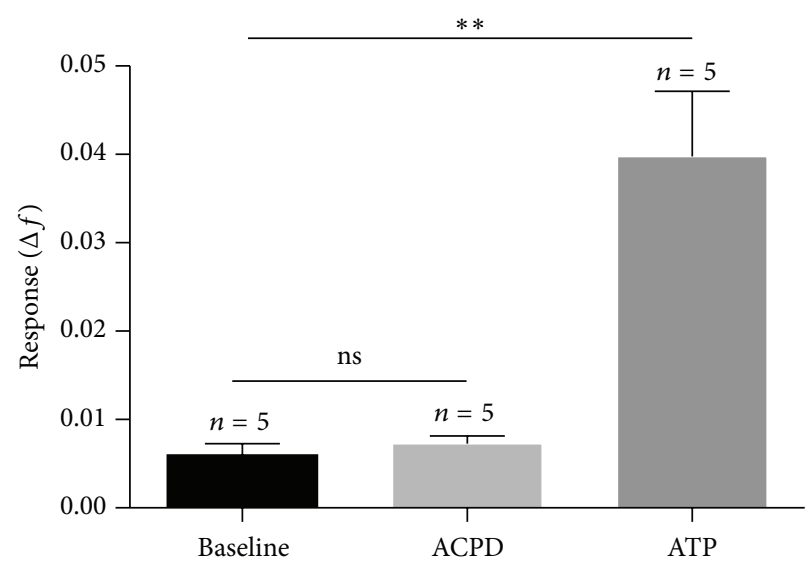

(d)

FIGURE 3: Effect of metabotropic glutamate receptor agonists DHPG and ACPD on retinal astrocytes $\left[\mathrm{Ca}^{2+}\right]_{\mathrm{i}}$ in situ. (a) Representative trace showing fura-2 fluorescence ratio of an astrocyte treated twice with $50 \mu \mathrm{M}$ DHPG followed by $10 \mu \mathrm{M}$ ATP. The astrocyte responded to ATP, but not DHPG. (b) The mean response elicited by DHPG was not significantly different from baseline, but the mean response elicited by ATP was. (c) Representative trace showing fura-2 fluorescence ratio of an astrocyte treated twice with $50 \mu \mathrm{M}$ ACPD followed by $10 \mu \mathrm{M}$ ATP. The astrocyte responded to ATP, but not ACPD. (d) Mean response elicited by ACPD application was not significantly different from baseline, while mean response elicited by ATP was. Error bars are SEM, $n=$ number of retinas studied, ns: not significant; ${ }^{* *} p<0.01$ at $\alpha=0.05$ as determined by Dunn's multiple comparison test following Kruskal-Wallis ANOVA.

but this difference was due solely to the effect of ATP (Dunn's multiple comparisons test; Figure 2(d)). Of the 179 astrocytes studied, only 4 cells (2\%) showed an increase in fura-2 fluorescence ratio of $\geq 0.02$ during treatment with $50 \mu \mathrm{M}$ ACPD. All cells (100\%) responded to $10 \mu \mathrm{M}$ ATP.

3.4. Effect of AMPA and NMDA on Retinal Astrocytes In Vitro. Thus far, the only glutamate receptor agonist that produced an increase in fura-2 fluorescence ratio in situ (in $45 \%$ of cells tested) was AMPA. To determine if the effect of AMPA in situ was due to a direct effect on astrocytes, we tested the effect of AMPA (and also NMDA) on astrocytes in vitro. Bath application of $10 \mu \mathrm{M}$ AMPA or $50 \mu \mathrm{M}$ NMDA did not elicit a significant response from isolated mouse retinal astrocytes (Figure 4). Figures 4(a) and 4(c) show traces from representative cells treated twice with AMPA or NMDA, respectively, and then with $10 \mu \mathrm{M}$ ATP. In both cases ATP increased the ratio of fura-2 fluorescence, but neither AMPA nor NMDA had an effect. Statistical analysis of the mean data revealed differences between baseline and the peak mean $\Delta f$ response to ATP (Figure 4(b), Kruskal-Wallis $H=8.769$, $p=0.0012$; Figure $4(\mathrm{~d}), H=9.980 ; p=0.0009$ ). The lack of an effect of AMPA on astrocytes in vitro suggests that the action of AMPA in situ may not be direct.

\section{Discussion}

The results of the present study provide evidence that mouse retinal astrocyte $\left[\mathrm{Ca}^{2+}\right]_{\mathrm{i}}$, assessed by fura- 2 imaging techniques, is not increased by the ionotropic and metabotropic glutamate receptor agonists NMDA, DHPG, and ACPD. Mean peak fura-2 fluorescence ratios during agonist applications were not different than fluctuations observed under baseline conditions. The one exception was AMPA. Although the increase in peak mean fura-2 fluorescence ratio, compared to baseline, was not statistically significant, about half (45\%) of all the cells studied showed an increase in fluorescence of $\geq 0.02$. (The number of such responding cells 


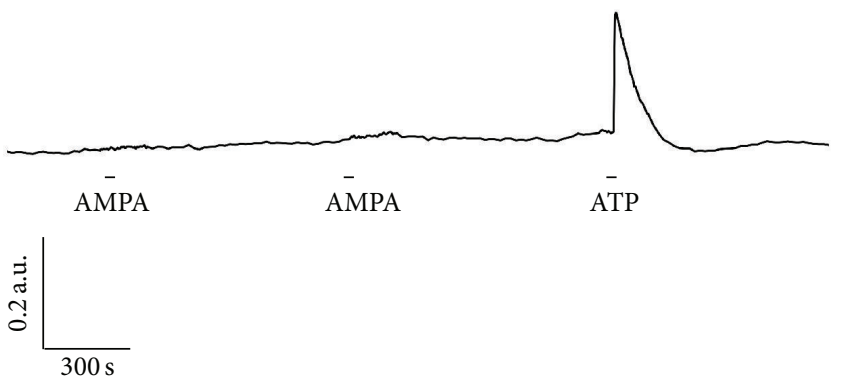

(a)

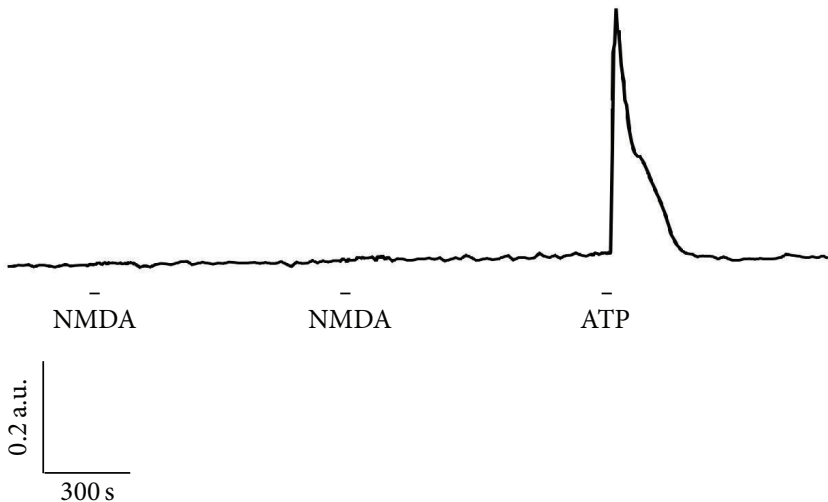

(c)

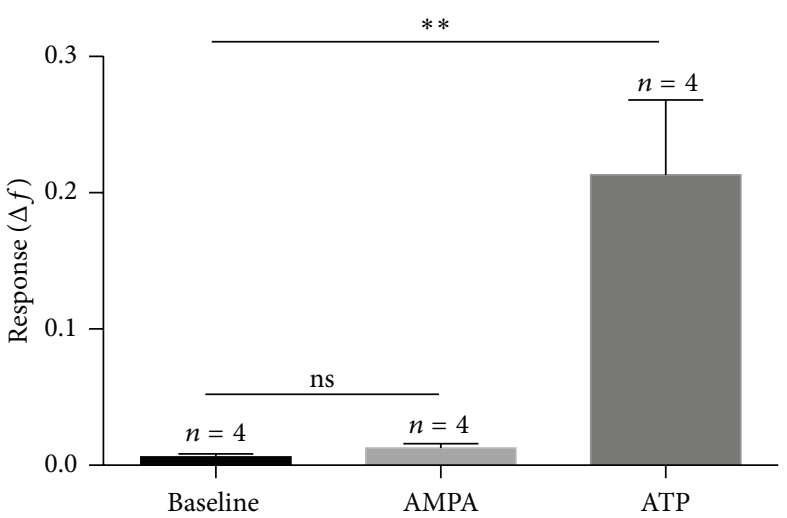

(b)

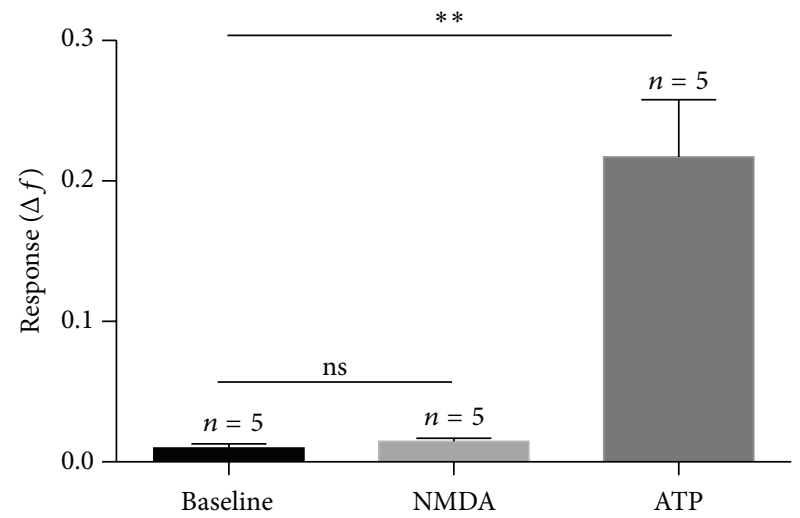

(d)

FIGURE 4: Effect of ionotropic glutamate receptor agonists AMPA and NMDA on retinal astrocytes $\left[\mathrm{Ca}^{2+}\right]_{\mathrm{i}}$ in vitro. (a) Representative trace showing fura- 2 fluorescence ratio of an astrocyte treated twice with $10 \mu \mathrm{M}$ AMPA followed by $10 \mu \mathrm{M}$ ATP. The astrocyte responded to ATP, but not AMPA. (b) The mean response elicited by AMPA was not significantly different from baseline, but the mean response elicited by ATP was. (c) Representative trace showing fura-2 fluorescence ratio of an astrocyte treated twice with $10 \mu \mathrm{M}$ NMDA followed by $10 \mu \mathrm{M}$ ATP. The astrocyte responded to ATP, but not NMDA. (d) Mean response elicited by NMDA application was not significantly different from baseline, while mean response elicited by ATP was. Error bars are SEM, $n=$ number of retinas studied, ns: not significant; ${ }^{* *} p<0.01$ at $\alpha=0.05$ as determined by Dunn's multiple comparison test following Kruskal-Wallis ANOVA.

in the case of each of the other agonists was only $2 \%$.) We concluded, therefore, that AMPA increases $\left[\mathrm{Ca}^{2+}\right]_{\mathrm{i}}$ in response to AMPA application in situ. To determine if the effect of AMPA was due to a direct effect on astrocytes, we examined the effect of AMPA on astrocytes in vitro. AMPA did not elicit a significant response from isolated mouse retinal astrocytes suggesting that the effect of AMPA in situ could be indirect.

Previous research has shown that astrocytes from the brain not only express ionotropic glutamate receptors $[1-3,5-$ $7,9-12]$ but also respond to ionotropic glutamate receptor agonists, both in vitro and in situ, including AMPA and NMDA $[10,26,27]$. In contrast, there are no studies examining the expression of glutamate receptor types expressed by retinal astrocytes and only two studies that have examined the effect of glutamate or AMPA/kainate glutamate receptor agonists on retinal astrocytes. Clark and Mobbs [20] reported that glutamate and AMPA/kainate receptor agonists evoked inward currents in rabbit retinal astrocytes in situ. This same study showed that glutamate-induced inward currents in retinal astrocytes were blocked by the AMPA/kainate receptor antagonist CNQX. In contrast, Newman and Zahs [19] reported that glutamate had no effect on rat retinal astrocyte $\left[\mathrm{Ca}^{2+}\right]_{\mathrm{i}}$ studied in situ, although glutamate did potentiate increases of $\left[\mathrm{Ca}^{2+}\right]_{i}$ produced by other stimuli. Our results are consistent with the results of Clark and Mobbs [20] in that we were able to demonstrate an effect of AMPA on mouse retinal astrocytes in situ. However, because AMPA was without effect on mouse retinal astrocytes in vitro, it is possible that the effect of AMPA in situ was indirect. AMPA acting at retinal neurons or Müller cells could result in transmitter, such as ATP or acetylcholine, release that, in turn, could increase astrocyte $\left[\mathrm{Ca}^{2+}\right]_{\mathrm{i}}[28-30]$.

We found that NMDA did not increase $\left[\mathrm{Ca}^{2+}\right]_{\mathrm{i}}$ in mouse retinal astrocytes in situ or in vitro. A common concern when studying NMDA receptors is extracellular $\mathrm{Mg}^{2+}$ block of the NMDA receptor [31]. Schipke et al. [27] showed that NMDA-induced currents in mouse neocortical astrocytes were enhanced in $\mathrm{Mg}^{2+}$-free conditions, reduced at $4 \mathrm{mM} \mathrm{Mg}^{2+}$, and abolished at $10 \mathrm{mM} \mathrm{Mg}^{2+}$. However, 
the same study showed that NMDA-induced currents were present, though of less magnitude, under standard recording conditions $\left(1.8 \mathrm{mM} \mathrm{Mg}^{2+}\right)$. In fact, several studies have shown that glial NMDA receptors are much less (or not) sensitive to $\mathrm{Mg}^{2+}$ block $[11,32]$. In our experiments, external $\mathrm{Mg}^{2+}$ was $0.8 \mathrm{mM}$. Whether or not $\mathrm{Mg}^{2+}$ block is an issue in mouse retinal astrocyte NMDA-dependent current or $\left[\mathrm{Ca}^{2+}\right]_{\mathrm{i}}$ increases deserves further investigation. Furthermore, the NMDA-induced calcium dynamics reported by Schipke et al. [27] were restricted to distal processes of the astrocytes and were not observed in the cell bodies. The focus of the present study was imaging of astrocyte somata, making it possible that responses occurred in distal processes that were not captured by our imaging.

Various types of ionotropic and metabotropic glutamate receptors are present on astrocytes in many different brain regions and, when activated, are often capable of increasing $\left[\mathrm{Ca}^{2+}\right]_{\mathrm{i}}$ (for review see [3]). That retinal astrocytes are different adds to evidence that astrocytes in the CNS are heterogeneous $[33,34]$. In fact, even though retinal astrocytes are immigrants from the optic nerve [35], astrocytes in the mouse optic nerve show increases in $\left[\mathrm{Ca}^{2+}\right]_{\mathrm{i}}$ in response to glutamate and a variety of ionotropic and metabotropic agonists [30]. Although there was a small direct effect of glutamate, much of the effect of glutamate on optic nerve astrocyte $\left[\mathrm{Ca}^{2+}\right]_{\mathrm{i}}$ was blocked by purinergic $\mathrm{P} 2$ receptor antagonists suggesting that the effect of glutamate was mediated largely by an indirect effect mediated by ATP [30]. Nonetheless, our data suggest that the calcium responses of retinal and optic nerve astrocytes to glutamate agonists are different, underlining the heterogeneity of astrocytes in different regions of the CNS. Perhaps this should not come as a surprise given that the astrocytes studied in the optic nerve [30] were likely to have been mostly type $1 \mathrm{~A}$ or type 2 astrocytes whereas retinal astrocytes are type $1 \mathrm{~B}[36,37]$.

Although our data suggest that glutamate is unlikely to be an important direct activator of retinal astrocytes, at least with respect to processes that would lead to elevated $\left[\mathrm{Ca}^{2+}\right]_{\mathrm{i}}$, it was clear that ATP was a potent and consistent elevator of $\left[\mathrm{Ca}^{2+}\right]_{\mathrm{i}}$ in mouse retinal astrocytes. Although the functional significance of elevated $\left[\mathrm{Ca}^{2+}\right]_{\mathrm{i}}$ in astrocytes remains controversial [38], it is possible that ATP-mediated increases of $\left[\mathrm{Ca}^{2+}\right]_{\mathrm{i}}$ in mouse retinal astrocytes are associated with activity that regulates neuronal or vascular functions. Although glutamate may not influence retinal astrocytes, ATP is not necessarily the only endogenous agent capable of increasing $\left[\mathrm{Ca}^{2+}\right]_{\mathrm{i}}$. As one example, we have preliminary evidence that the potent vasoactive peptide, endothelin-1, increases $\left[\mathrm{Ca}^{2+}\right]_{\mathrm{i}}$ in rat retinal astrocytes in situ [39].

\section{Competing Interests}

The authors declare that they have no competing interests.

\section{Acknowledgments}

The authors acknowledge the technical assistance of Ms. Janette Nason. This work was supported by a grant from the
Natural Science and Engineering Research Council (NSERC) to William H. Baldridge and Canadian Institutes of Health Research (CIHR), Nova Scotia Health Research Foundation, and Nova Scotia Graduate Scholarships to Stephanie N. Blandford.

\section{References}

[1] J. T. Porter and K. D. McCarthy, "Astrocytic neurotransmitter receptors in situ and in vivo," Progress in Neurobiology, vol. 51, no. 4, pp. 439-455, 1997.

[2] U. Lalo, Y. Pankratov, V. Parpura, and A. Verkhratsky, "Ionotropic receptors in neuronal-astroglial signalling: what is the role of 'excitable' molecules in non-excitable cells," Biochimica et Biophysica Acta: Molecular Cell Research, vol. 1813, no. 5, pp. 992-1002, 2011.

[3] V. Parpura and A. Verkhratsky, "Astroglial amino acid-based transmitter receptors," Amino Acids, vol. 44, no. 4, pp. 1151-1158, 2013.

[4] C. Agulhon, J. Petravicz, A. B. McMullen et al., "What is the role of astrocyte calcium in neurophysiology?" Neuron, vol. 59, no. 6, pp. 932-946, 2008.

[5] A. H. Cornell-Bell, S. M. Finkbeiner, M. S. Cooper, and S. J. Smith, "Glutamate induces calcium waves in cultured astrocytes: long-range glial signaling," Science, vol. 247, no. 4941, pp. 470-473, 1990.

[6] J. T. Porter and K. D. McCarthy, "Hippocampal astrocytes in situ respond to glutamate released from synaptic terminals," The Journal of Neuroscience, vol. 16, no. 16, pp. 5073-5081, 1996.

[7] M. Zonta, A. Sebelin, S. Gobbo, T. Fellin, T. Pozzan, and G. Carmignoto, "Glutamate-mediated cytosolic calcium oscillations regulate a pulsatile prostaglandin release from cultured rat astrocytes," The Journal of Physiology, vol. 553, part 2, pp. 407414, 2003.

[8] G. Queiroz, P. J. Gebicke-Haerter, A. Schobert, K. Starke, and I. Von Kügelgen, "Release of ATP from cultured rat astrocytes elicited by glutamate receptor activation," Neuroscience, vol. 78, no. 4, pp. 1203-1208, 1997.

[9] J.-P. Mothet, L. Pollegioni, G. Ouanounou, M. Martineau, P. Fossier, and G. Baux, "Glutamate receptor activation triggers a calcium-dependent and SNARE protein-dependent release of the gliotransmitter D-serine," Proceedings of the National Academy of Sciences of the United States of America, vol. 102, no. 15, pp. 5606-5611, 2005.

[10] M. K. Shelton and K. D. McCarthy, "Mature hippocampal astrocytes exhibit functional metabotropic and ionotropic glutamate receptors in situ," Glia, vol. 26, no. 1, pp. 1-11, 1999.

[11] U. Lalo, Y. Pankratov, F. Kirchhoff, R. A. North, and A. Verkhratsky, "NMDA receptors mediate neuron-to-glia signaling in mouse cortical astrocytes," Journal of Neuroscience, vol. 26, no. 10, pp. 2673-2683, 2006.

[12] O. Palygin, U. Lalo, A. Verkhratsky, and Y. Pankratov, "Ionotropic NMDA and $\mathrm{P} 2 \mathrm{X} 1 / 5$ receptors mediate synaptically induced $\mathrm{Ca}^{2+}$ signalling in cortical astrocytes," Cell Calcium, vol. 48, no. 4, pp. 225-231, 2010.

[13] E. Newman and A. Reichenbach, "The Muller cell: a functional element of the retina," Trends in Neurosciences, vol. 19, no. 8, pp. 307-312, 1996.

[14] E. A. Newman, "Calcium signaling in retinal glial cells and its effect on neuronal activity," Progress in Brain Research, vol. 132, pp. 241-254, 2001. 
[15] J. Kur and E. A. Newman, "Purinergic control of vascular tone in the retina," Journal of Physiology, vol. 592, no. 3, pp. 491-504, 2014.

[16] M. R. Metea and E. A. Newman, "Glial cells dilate and constrict blood vessels: a mechanism of neurovascular coupling," The Journal of Neuroscience, vol. 26, no. 11, pp. 2862-2870, 2006.

[17] M. Wakakura and N. Yamamoto, "Cytosolic calcium transient increase through the AMPA/kainate receptor in cultured Müller cells," Vision Research, vol. 34, no. 9, pp. 1105-1109, 1994.

[18] S. A. Keirstead and R. F. Miller, "Metabotropic glutamate receptor agonists evoke calcium waves in isolated muller cells," Glia, vol. 21, no. 2, pp. 194-203, 1997.

[19] E. A. Newman and K. R. Zahs, "Calcium waves in retinal glial cells," Science, vol. 275, no. 5301, pp. 844-845, 1997.

[20] B. Clark and P. Mobbs, "Transmitter-operated channels in rabbit retinal astrocytes studied in situ by whole-cell patch clamping," Journal of Neuroscience, vol. 12, no. 2, pp. 664-673, 1992.

[21] J. Yu, B. A. Daniels, and W. H. Baldridge, "Slow excitation of cultured rat retinal ganglion cells by activating group I metabotropic glutamate receptors," Journal of Neurophysiology, vol. 102, no. 6, pp. 3728-3739, 2009.

[22] B. A. Daniels and W. H. Baldridge, "D-Serine enhancement of NMDA receptor-mediated calcium increases in rat retinal ganglion cells," Journal of Neurochemistry, vol. 112, no. 5, pp. 1180-1189, 2010.

[23] K. L. Briggman and T. Euler, "Bulk electroporation and population calcium imaging in the adult mammalian retina," Journal of Neurophysiology, vol. 105, no. 5, pp. 2601-2609, 2011.

[24] B. A. Daniels, L. Wood, F. Tremblay, and W. H. Baldridge, "Functional evidence for D-serine inhibition of non-N-methylD-aspartate ionotropic glutamate receptors in retinal neurons," European Journal of Neuroscience, vol. 35, no. 1, pp. 56-65, 2012.

[25] A. Serrano, N. Haddjeri, J.-C. Lacaille, and R. Robitaille, "GABAergic network activation of glial cells underlies hippocampal heterosynaptic depression," The Journal of Neuroscience, vol. 26, no. 20, pp. 5370-5382, 2006.

[26] C. L. Bowman and H. K. Kimelberg, "Excitatory amino acids directly depolarize rat brain astrocytes in primary culture," Nature, vol. 311, no. 5987, pp. 656-659, 1984.

[27] C. G. Schipke, C. Ohlemeyer, M. Matyash, C. Nolte, H. Kettenmann, and F. Kirchhoff, "Astrocytes of the mouse neocortex express functional N-methyl-D-aspartate receptors," The FASEB Journal, vol. 15, no. 7, pp. 1270-1272, 2001.

[28] A. Araque, E. D. Martín, G. Perea, J. I. Arellano, and W. Buño, "Synaptically released acetylcholine evokes $\mathrm{Ca}^{2+}$ elevations in astrocytes in hippocampal slices," The Journal of Neuroscience, vol. 22, no. 7, pp. 2443-2450, 2002.

[29] E. A. Newman, "A dialogue between glia and neurons in the retina: modulation of neuronal excitability," Neuron Glia Biology, vol. 1, no. 3, pp. 245-252, 2004.

[30] N. Hamilton, S. Vayro, F. Kirchhoff et al., "Mechanisms of ATPand glutamate-mediated calcium signaling in white matter astrocytes," Glia, vol. 56, no. 7, pp. 734-749, 2008.

[31] M. L. Mayer, G. L. Westbrook, and P. B. Guthrie, "Voltagedependent block by $\mathrm{Mg}^{2+}$ of NMDA responses in spinal cord neurones," Nature, vol. 309, no. 5965, pp. 261-263, 1984.

[32] D. Žiak, A. Chvátal, and E. Syková, "Glutamate-, kainate- and NMDA-evoked membrane currents in identified glial cells in rat spinal cord slice," Physiological Research, vol. 47, no. 5, pp. 365-375, 1998.
[33] V. Matyash and H. Kettenmann, "Heterogeneity in astrocyte morphology and physiology," Brain Research Reviews, vol. 63, no. 1-2, pp. 2-10, 2010.

[34] Y. Zhang and B. A. Barres, "Astrocyte heterogeneity: an underappreciated topic in neurobiology," Current Opinion in Neurobiology, vol. 20, no. 5, pp. 588-594, 2010.

[35] T. Watanabe and M. C. Raff, "Retinal astrocytes are immigrants from the optic nerve," Nature, vol. 332, no. 6167, pp. 834-837, 1988.

[36] R. H. Miller, S. David, R. Patel, E. R. Abney, and M. C. Raff, "A quantitative immunohistochemical study of macroglial cell development in the rat optic nerve: in vivo evidence for two distinct astrocyte lineages," Developmental Biology, vol. 111, no. 1, pp. 35-41, 1985.

[37] H. Ye and M. R. Hernandez, "Heterogeneity of astrocytes in human optic nerve head," Journal of Comparative Neurology, vol. 362, no. 4, pp. 441-452, 1995.

[38] N. Bazargani and D. Attwell, "Astrocyte calcium signaling: the third wave," Nature Neuroscience, vol. 19, no. 2, pp. 182-189, 2016.

[39] L. P. de Sevilla Muller, B. C. Chauhan, and W. H. Baldridge, "Effect of endothelin 1 (ET-1) on the calcium dynamics of rat retinal astrocytes," Investigative Ophthalmology \& Visual Science, vol. 52, Article ID 1851, 2011. 


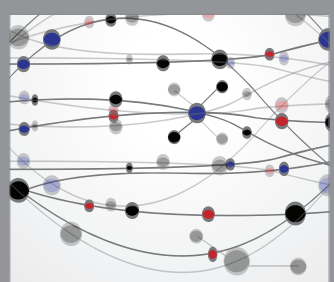

The Scientific World Journal
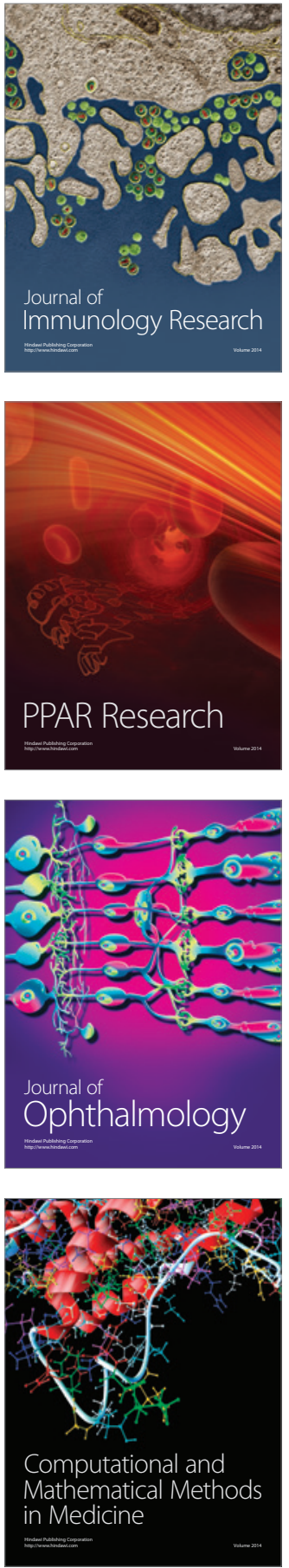

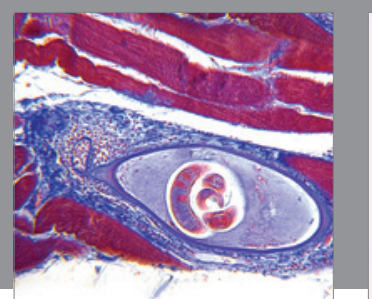

Gastroenterology Research and Practice

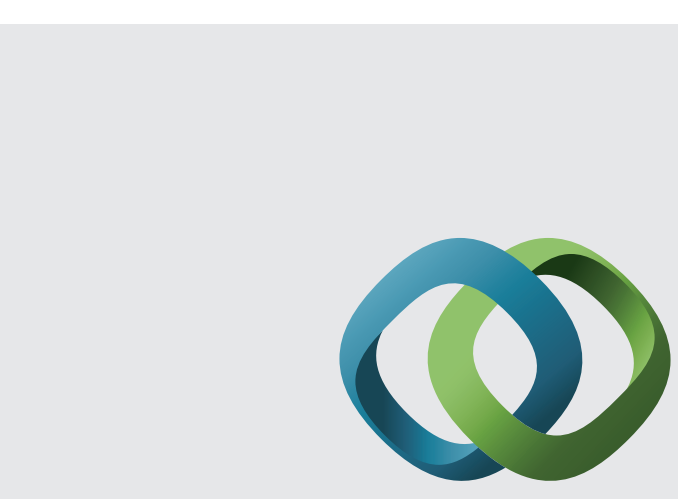

\section{Hindawi}

Submit your manuscripts at

http://www.hindawi.com
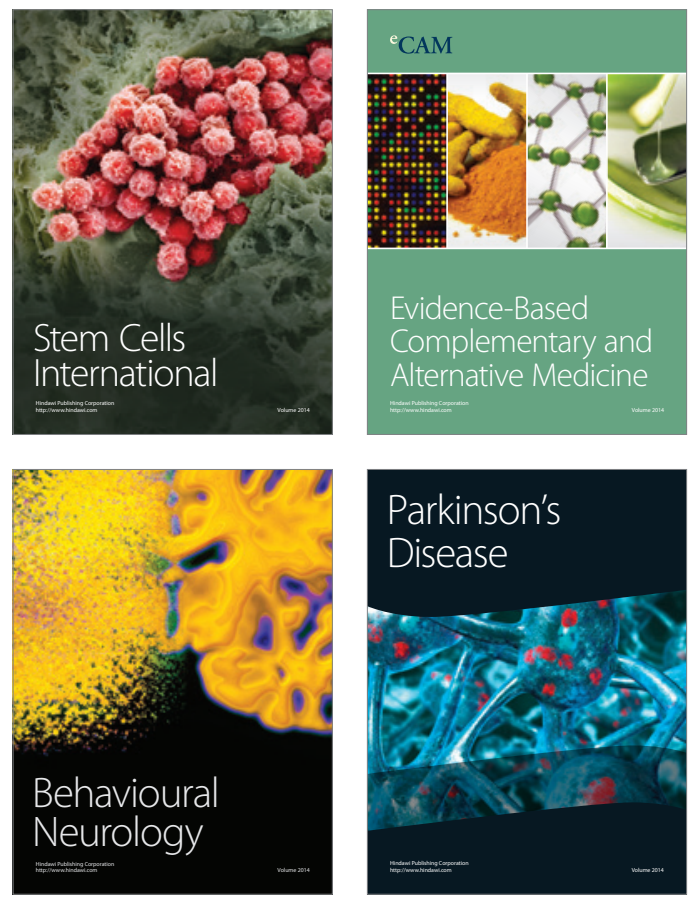
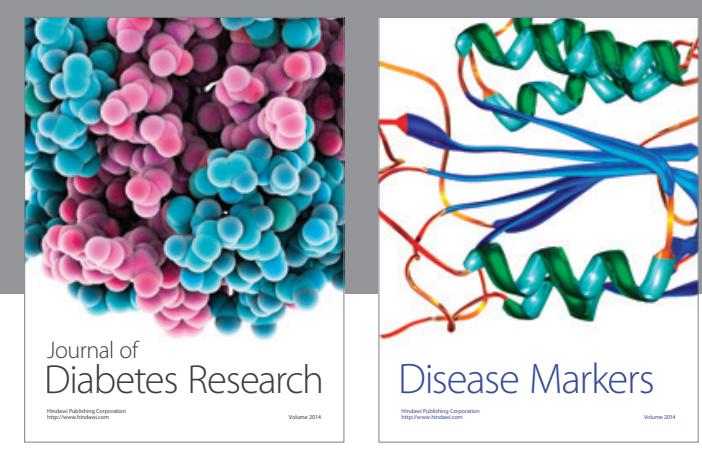

Disease Markers
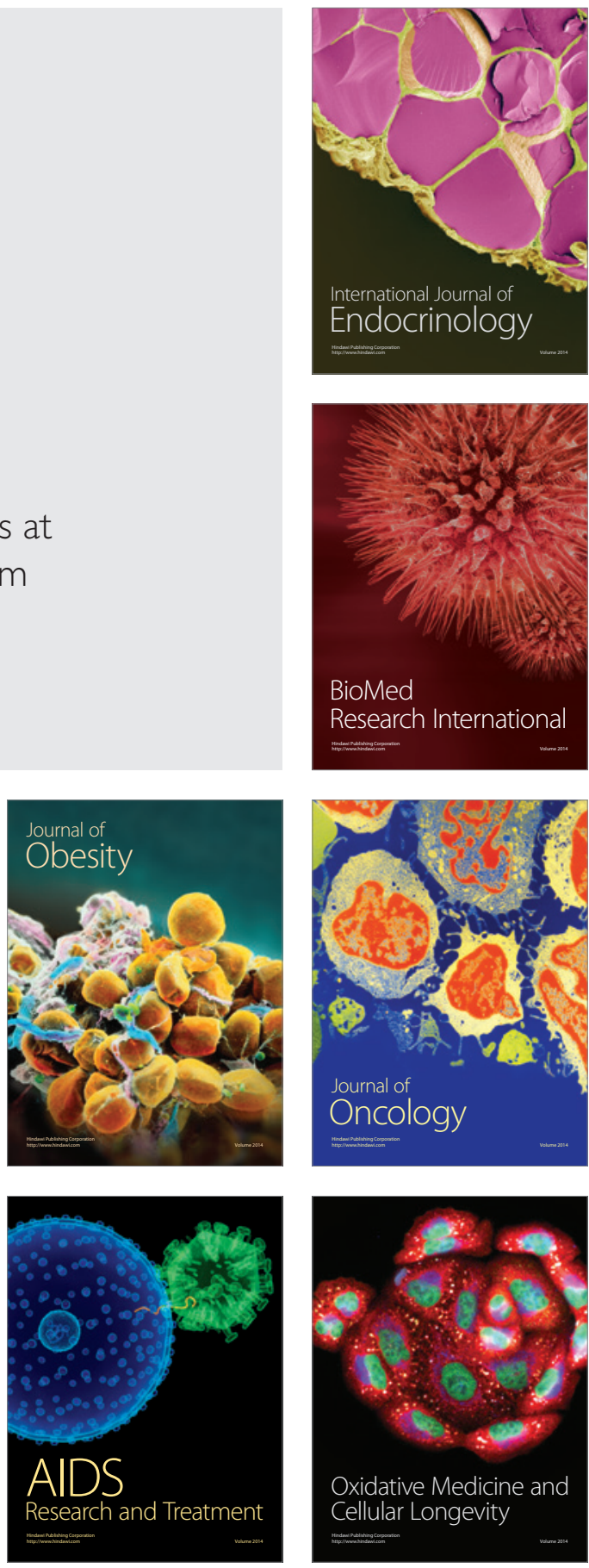